\title{
Study on Optimization of Working Performance of Ultra High Performance Concrete
}

\author{
Wang Shengyu ${ }^{1,2, *}$, , Zhan Yijian ${ }^{1,2}$ \\ ${ }^{1}$ Shanghai Construction Group Co., Ltd, Shanghai 200080, China \\ ${ }^{2}$ Shanghai Engineering Research Center of Mega Structure High Performance Concrete
}

\begin{abstract}
The water binder ratio is a key parameter in the mix design of ultra-high performance concrete. Aiming at the high sensitivity of ultra-high performance concrete to water consumption, the influence of water consumption on the performance of ultra-high performance concrete was studied in a narrow range. The compatibility ratio of raw materials of ultra-high performance concrete can be adjusted, but the space is small, so we try to improve the fluidity of concrete by physical and chemical means. The experimental results show that the fluidity of concrete increases slightly with the addition of glass beads, but the flexural properties of the concrete are adversely affected. With the addition of viscosity reducer, the workbility of concrete increases, but the compressive strength decreases.
\end{abstract}

\section{Analysis of Mix Proportion Charac teristics of Ultra-High Performance Co ncrete}

Ultra-high performance concrete (UHPC) is a kind of UHPC with excellent performance and good durability. It has ultra high toughness and strength, which is far beyond ordinary high performance concrete. Thanks to the unremitting efforts of scientific researchers, UHPC has been gradually applied to such occasions as high-rise buildings, long-span bridges, military projects, water conservancy projects, special structures and prefabricated component nodes.

Different from the conventional concrete mix proportion, the mix proportion of UHPC carries the following features: ultra-low water binder ratio ${ }^{[1]}{ }^{[2]}$, ultra-high cement content, adding nano mineral admixture (silica fume) and eliminating defective aggregate (stone). Nano silica fume improves the particle size distribution of cementitious materials and makes the UHPC paste in a dense state, which serves as the main reason to explain why its strength is far higher than that of ordinary UHPC. The traditional strength design formula of Bowromi Water Binder Ratio was put forward when the ordinary concret is in the state of multi hole hardened mortar, so it is not suitable for UHPC paste whose hardened paste is in a dense state. Because there is no defective aggregate (stone) in the mix proportion of UHPC, and the surface area of sand is quite different from that of stone particles, so the method of determining the fluidity of concrete according to stone particle size and water content in the existing national standard "Specification for Mix Proportion Design of Ordinary Concrete" (JGJ55-2011) is not feasible. The existing mix proportion design methods of particle pie model are based on the packing density of cementitious materials, while neglecting the influence of the fluidity of fresh mortar and the hydration reaction on the fluidity of concrete. $^{[3]}$ At present, the UHPC used in engineering shows poor fluidity and fast fluidity loss. These are the main problems hindering the wide application of UHPC. Therefore, it is necessary to optimize the mix proportion of UHPC to form a mix proportion scheme and to meet the needs in work.

\section{Raw Materials for Experiment}

The cement used in the experiment-P II 52.5 Portland cement, is produced by Anhui Conch Cement Co., Ltd.; the silica fume-densified silica fume, is produced by Shanghai Topken Silica Fume Co., LTD; the superplasticizer - SQIIC803 polycarboxylate superplasticizer (retarding type) is produced by Shanghai Construction Building Materials Technology Group Co., Ltd., and its solid content is $22.57 \%$ and the water reduction rate of concrete is greater than or equals to 25\%; high strength PVA fiber is made by Changzhou Tian Yi Engineering Fiber Co., Ltd., its basic properties are shown in Table 1. The microfilament steel fiber is provided by Shanghai Real Strong Fiber Co., Ltd., and the basic properties are shown in Table 2:

* Corresponding author: 326956120@qq.com 
Table 1 Performance of high strength PVA fiber

\begin{tabular}{ccccc}
\hline & Diamete $(\mu \mathrm{m})$ & Elongation $(\%)$ & Breaking strength $(\mathrm{MPa})$ & Density $\left(\mathrm{g} / \mathrm{cm}^{3}\right)$ \\
\hline High strength PVA fiber & $12-14$ & $6.0-8.0$ & $\geq 1000$ & 1.30 \\
\hline & Table 2 & Properties of copper plated & & \\
\hline & Diameter $(\mathrm{mm})$ & Aspect ratio & Tensile strength (MPa) & Number of fibers $(\approx$ piece $/ \mathrm{Kg})$ \\
\hline \multirow{2}{*}{ Microfilament steel fiber } & 0.22 & 60 & 2850 & 224862
\end{tabular}

The glass beads in the experiment, a kind of glass bead for grinding, are produced by Hebei Langfang Daohong Glassbeads Co., Ltd. And the particle sizes are The viscosity reducer is Rheoplus 416 polycarboxylate ether concrete viscosity reducer, and it is produced by BASF SE. The appearance of glass beads, viscosity $0.15-0.16 \mathrm{~mm}, 0.2-0.3 \mathrm{~mm}$ and $0.45-0.6 \mathrm{~mm}$ respectively. reducer and PVA fiber can be seen in Fig. 1, 2 and 3:

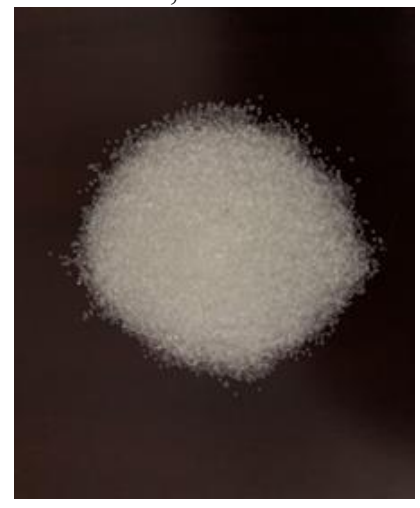

Fig. 1. Glass beads

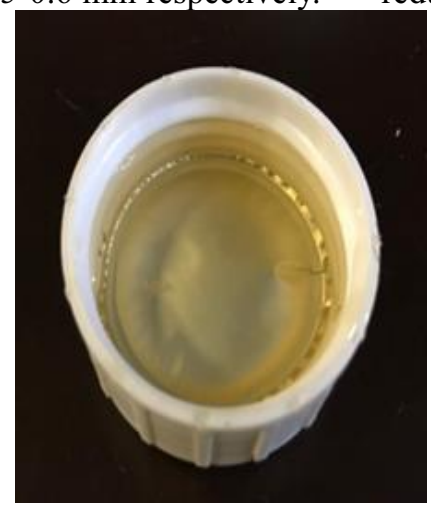

Fig. 2. Viscosity reducer

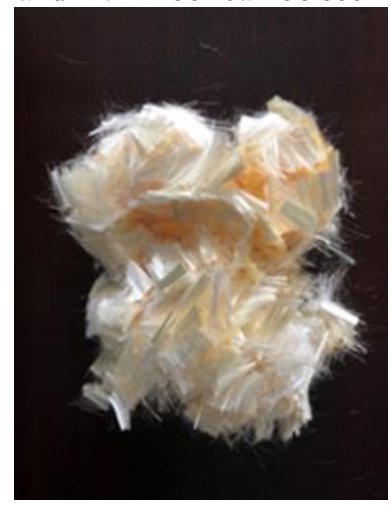

Fig. 3. PVA fiber

\section{Experimental Contents}

\subsection{Experimental Mix Proportion}

The effects of water consumption, glass beads and viscosity reducer on the workability of UHPC are investigated. After that, the writer analyzes feasible ways to optimize the performance of UHPC.

In the experiment of water consumption, considering that the fluidity of linear fiber reinforced concrete is generally high, a $13 \mathrm{~mm}$ long end hook type copper plated microfilament steel fiber is used. The experimental mix proportion can be seen in Table 3:

Table 3 Experimental mix proportion of water binder ratio

\begin{tabular}{|c|c|c|c|c|c|c|c|}
\hline No. & Water(g) & Silica fume (g) & Cement(g) & $\begin{array}{l}\text { Standard } \\
\text { sand }(g)\end{array}$ & Plasticizer(g) & $\begin{array}{l}\text { Fiber volume } \\
\text { fraction }(\%)\end{array}$ & Fiber contents $(\mathrm{g})$ \\
\hline $\begin{array}{l}\text { ST }(13 \mathrm{~mm}) \text { end } \\
\text { hook }\end{array}$ & 175 & 50 & 1000 & 1000 & 40 & $1 \%$ & 84.3 \\
\hline $\begin{array}{l}\text { ST }(13 \mathrm{~mm}) \text { end } \\
\text { hook }\end{array}$ & 185 & 50 & 1000 & 1000 & 40 & $1 \%$ & 84.3 \\
\hline $\begin{array}{l}\text { ST }(13 \mathrm{~mm}) \text { end } \\
\text { hook }\end{array}$ & 195 & 50 & 1000 & 1000 & 40 & $1 \%$ & 84.3 \\
\hline $\begin{array}{l}\text { ST }(13 \mathrm{~mm}) \text { end } \\
\text { hook }\end{array}$ & 205 & 50 & 1000 & 1000 & 40 & $1 \%$ & 84.3 \\
\hline
\end{tabular}

In the modification experiment of glass beads, the effect of glass beads with different particle sizes on the fluidity of ultra-high toughness and strength concrete is

mainly studied ${ }^{[4]}$. The fibers added are $9 \mathrm{mmPVA}$ fibers. The experimental mix proportion can be seen in Table 4:

Table 4 Mix proportion of concrete with glass beads

\begin{tabular}{ccccccccc}
\hline & Water & $\begin{array}{c}\text { Silica } \\
\text { fume }\end{array}$ & Cement & Sand & Plasticizer & $\begin{array}{c}\text { Fiber } \\
\text { volume } \\
\text { fraction }\end{array}$ & $\begin{array}{c}\text { Fiber } \\
\text { contents }\end{array}$ & Glass beads \\
\cline { 2 - 8 } & $(\mathrm{g})$ & $(\mathrm{g})$ & $(\mathrm{g})$ & $(\mathrm{g})$ & $(\mathrm{g})$ & $(\%)$ & $\begin{array}{c}\text { Particle size } \\
(\mathrm{mm})\end{array}$ & $\begin{array}{c}\text { Addition contents } \\
(\mathrm{g})\end{array}$ \\
\hline WZ-0 & 195 & 50 & 1000 & 1000 & 40 & $1 \%$ & 14 & 0 \\
WZ-1 & 195 & 50 & 1000 & 1000 & 40 & $1 \%$ & 14 & $0.15-0.16$
\end{tabular}




$\begin{array}{llllllllll}\text { WZ-2 } & 195 & 50 & 1000 & 1000 & 40 & 1 \% & 14 & 0.2-0.3 & 150 \\ \text { WZ-3 } & 195 & 50 & 1000 & 1000 & 40 & 1 \% & 14 & 0.45-0.6 & 150\end{array}$

In the experiment of viscosity reducer modification, the effect of typical viscosity reducer with different contents on the fluidity of UHPC is mainly studied. The fibers are $9 \mathrm{~mm}$ pva fiber, and viscosity-reducer 416 is

Table 5 Mix proportion of concrete mixed with viscosity reducer

\begin{tabular}{cccccccccc}
\hline & Water & $\begin{array}{c}\text { Silica } \\
\text { fume }\end{array}$ & Cement & Sand & Plasticizer & $\begin{array}{c}\text { Fiber volume } \\
\text { fraction }\end{array}$ & $\begin{array}{c}\text { Fiber } \\
\text { contents }\end{array}$ & \multicolumn{2}{c}{ Viscosity reducer BASF416 } \\
\cline { 2 - 9 } & $(\mathrm{g})$ & $(\mathrm{g})$ & $(\mathrm{g})$ & $(\mathrm{g})$ & $(\mathrm{g})$ & $(\%)$ & $(\mathrm{g})$ & $\begin{array}{c}\text { Contents ratio } \\
\text { in solid }\end{array}$ & $\begin{array}{c}\text { Addition contents } \\
(\mathrm{g})\end{array}$ \\
\hline $\mathrm{JN}-0$ & 195 & 50 & 1000 & 1000 & 40 & $1 \%$ & 14 & 0 & 0 \\
$\mathrm{JN}-1$ & 195 & 50 & 1000 & 1000 & 40 & $1 \%$ & 14 & $15 \%$ & 50 \\
$\mathrm{JN}-2$ & 195 & 50 & 1000 & 1000 & 40 & $1 \%$ & 14 & $30 \%$ & 50 \\
$\mathrm{JN}-3$ & 195 & 50 & 1000 & 1000 & 40 & $1 \%$ & 14 & $45 \%$ & 50 \\
\hline
\end{tabular}

\subsection{Preparation of Ultra High Performance Co ncrete}

(1) According to the experimental mix proportion, weigh the raw materials, then pour the cement, silica fume and standard sand into the mortar mixer, and dry mix for 3-5 minutes (without water) until they are smooth.

(2) During the mixing, slowly add the mixing water and plasticizer, and stir them for 3-5 minutes until the mixture flows.

(3) Keeping the mixer on. During the process, put in fibers in batches, and mix well.

(4) After shaping the mixture, and vibrating and compacting it with cement mortar vibration table, then moved it into the curing box $(20 \pm 2){ }^{\circ} \mathrm{C}$.

\subsection{Test Methods for Ultra High Performance Concrete}

(1) Fluidity of mortar: Referring to GB/T2419-2005 Text Method for Fluidity of Cement Mortar.

(2) Bending strength and compression strength: Referring to GB/T 17671 -1999 Method of testing cements--Determination of strength. The bending strength test is conducted for the sample first, and then the compressive strength test is conducted for each section after fracture.

\section{Research on the Influence of Water Binder Ratio on the Performance of Concrete with Ultra High Toughness and Strength}

The flow performance and mechanical properties of UHPC with different water consumption are shown in

Table 6 Flow performance and mechanical properties of concrete with different water binder ratios

\begin{tabular}{cccc}
\hline $\begin{array}{c}\text { Water } \\
\text { Consumption }(\mathrm{g})\end{array}$ & $\begin{array}{c}\text { Fluidity } \\
(\mathrm{mm})\end{array}$ & $\begin{array}{c}1 \mathrm{~d} \text { bending } \\
\text { strength (MPa) }\end{array}$ & $\begin{array}{c}\text { 1d compressive } \\
\text { strength (MPa) }\end{array}$ \\
\hline
\end{tabular}
Table 6: added by $15 \%, 30 \%$ and $45 \%$ of the solid content of the admixture respectively. The experimental mix proportion can be seen in Table 5:

\begin{tabular}{llll}
\hline 175 & 147 & 4.6 & 11.6 \\
185 & 215 & 12.7 & 43.2 \\
195 & 225 & 14.0 & 45.3 \\
205 & 280 & 2.1 & 5.3 \\
\hline
\end{tabular}

The influence of water consumption on the flow performance of UFPC can be seen in Figure 4:

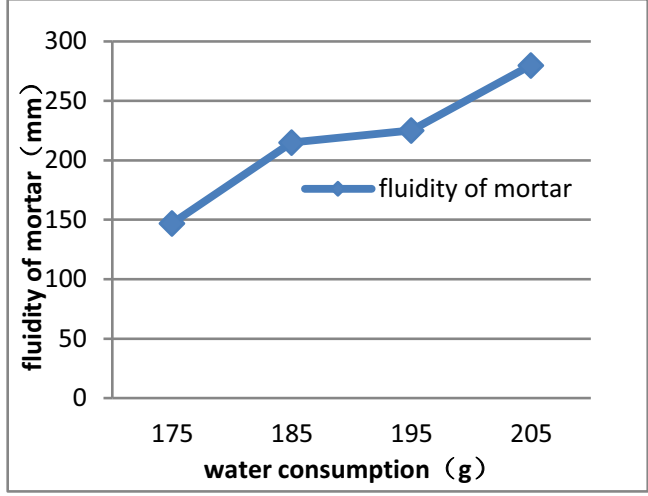

Fig. 4. Influence law of water consumption on flow performance of concrete

The influence of water consumption on the flow performance of UHPC can be seen in Fig. 5 and Fig. 6:

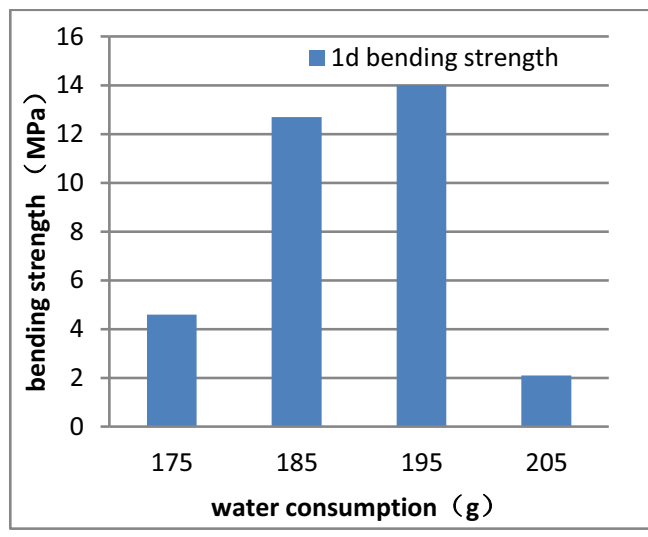

Fig. 5. Influence of water consumption on $1 \mathrm{~d}$ bending strength 


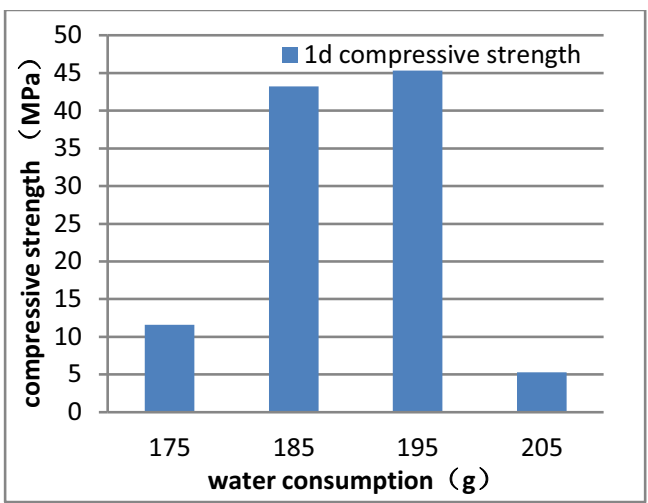

Fig. 6. Influence of water consumption on $1 \mathrm{~d}$ compressive strength

As can be seen from the above figures, with the increase of water content in UHPC, the fluidity of the concrete presents an obvious increasing trend. Although the fluidity of concrete presents an increasing trend, from the perspective of mechanical properties, the bending strength and compressive strength both show a trend of increasing first and then decreasing, and the peak value is more obvious. When there exists little moisture, most of the cement in the concrete does not participate in the hydration reaction, and the hydration part is discontinuous, which is the main reason for the low strength. When the water consumption reaches $205 \mathrm{~g}$, the mechanical properties of concrete show a significant decline. This is related to the larger dispersion of cement and the longer setting time after the addition of excess water. Excess water will seriously affect the strength of UHPC in the early stage.

\section{Research on the Influence of Glass Beads on the Performance of Ultra High Performance Concrete}

The variation law of various properties about UHPC with different particle sizes of glass beads can be shown in Table 7:

Table 7 Performance of Concrete with the Addition of Glass Beads

\begin{tabular}{cccc}
\hline No. & $\begin{array}{c}\text { Fluidity } \\
(\mathrm{mm})\end{array}$ & $\begin{array}{c}\text { 1d bending } \\
\text { strength(MPa) }\end{array}$ & $\begin{array}{c}\text { 1d compressive } \\
\text { strength(MPa) }\end{array}$ \\
\hline WZ-0 & 125.5 & 9.3 & 62.3 \\
WZ-1 & 120 & 8.6 & 58.8 \\
WZ-2 & 130 & 8.5 & 57.0 \\
WZ-3 & 130 & 8.7 & 50.3 \\
\hline
\end{tabular}

The influence of the particle size of glass beads on the fluidity of UHPC is shown in Figure 7:

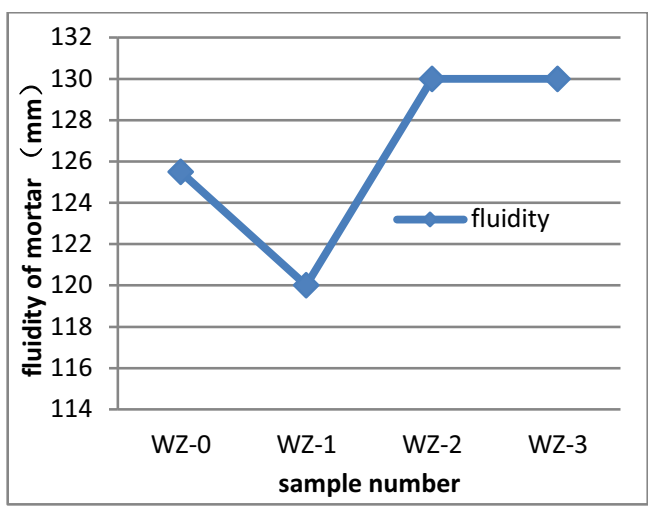

Fig. 7. Variation of mortar fluidity with the particle size of glass beads

The influence of the different particle sizes of glass beads on the mechanical properties of UHPC can be seen in Fig. 8 and Fig. 9:

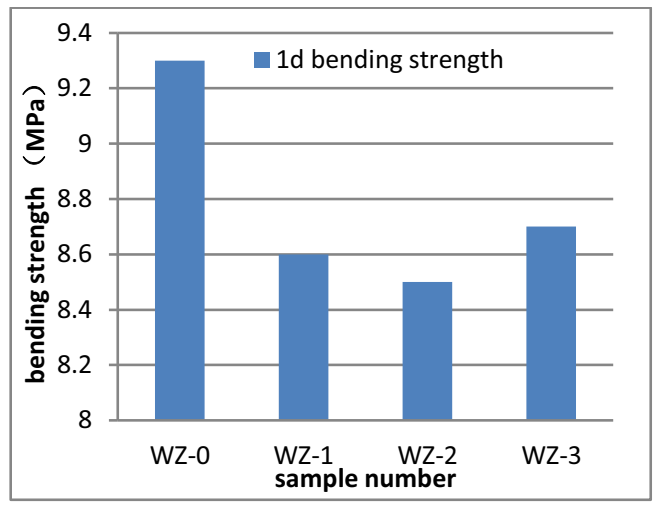

Fig. 8. Variation of bending strength with the diameter of glass

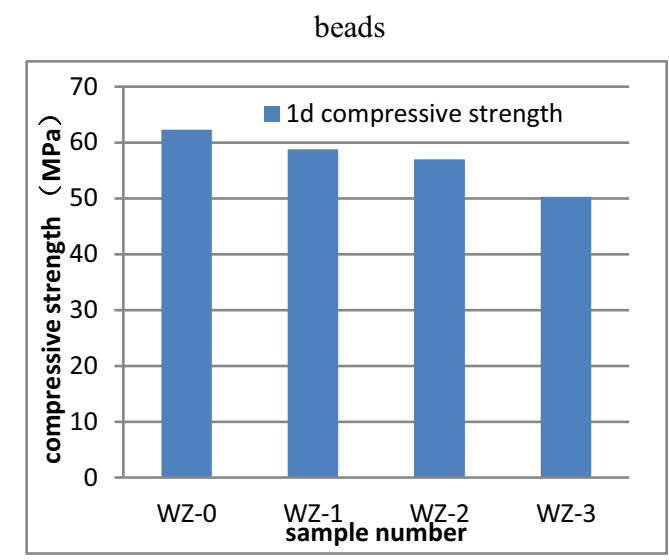

Fig.9. Variation of compressive strength with particle size of glass beads

It can be seen from the above information that after adding glass beads into UHPC, the flow performance of concrete increases slightly when the particle size of glass beads is relatively large, but the improvement is not obvious, and the concrete is in a relatively loose state. After the addition of glass beads, the mechanical properties of concrete decrease, while the bending strength decrease significantly, which indicate that glass beads produce great influence on the bending and tensile properties of concrete. The glass beads are spherical, and 
no obvious displacement occurs under vertical pressure load, so they have little effect on the compressive strength of concrete. When the concrete is subjected to shear load, the glass beads in the shear stress concentration area are easy to rotate or displace and embed into the micro cracks of concrete, which is also the main reason for the obvious decline of bending and tensile properties.

\section{Study on the Influence of Viscosit y Reducing Superplasticizer on the $P$ erformance of Ultra High Performance Concrete}

The variation of the properties of UHPC with the addition of viscosity reducer can be seen in Table 8:

Table 8 Performance of concrete with viscosity reducer

\begin{tabular}{cccc}
\hline No. & $\begin{array}{c}\text { Fluidity } \\
(\mathrm{mm})\end{array}$ & $\begin{array}{c}\text { 1d bending } \\
\text { strength(MPa) }\end{array}$ & $\begin{array}{c}\text { 1d compressive } \\
\text { strength(MPa) }\end{array}$ \\
\hline $\mathrm{JN}-0$ & 125.5 & 9.3 & 2.3 \\
$\mathrm{JN}-1$ & 115 & 9.4 & 48.1 \\
$\mathrm{JN}-2$ & 125 & 7.4 & 36.7 \\
$\mathrm{JN}-3$ & 130 & 7.7 & 33.1 \\
\hline
\end{tabular}

The influence of viscosity reducer content on the flow performance of UHPC is shown in Figure 10:

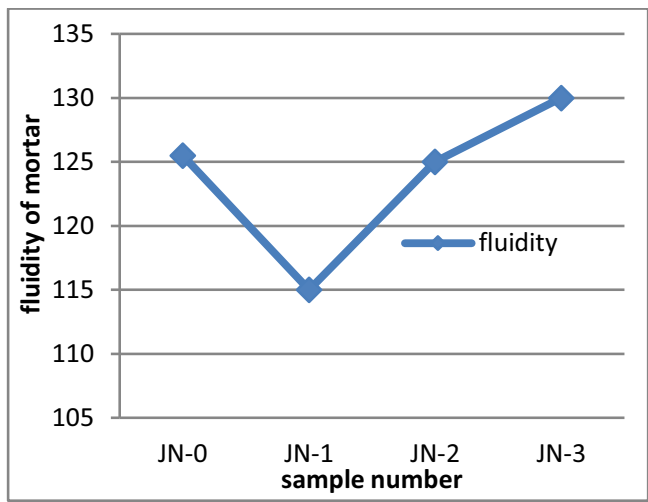

Fig. 10. Variation law of mortar fluidity with the content of

$$
\text { viscosity reducer }
$$

The influence of viscosity reducer content on the mechanical properties of UHPC can be seen in Fig. 11 and Fig. 12:

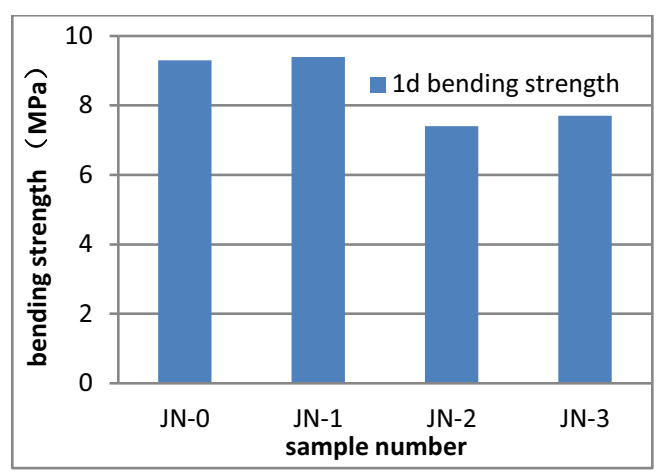

Fig.11. Variation of bending strength with changing viscosity reducer content

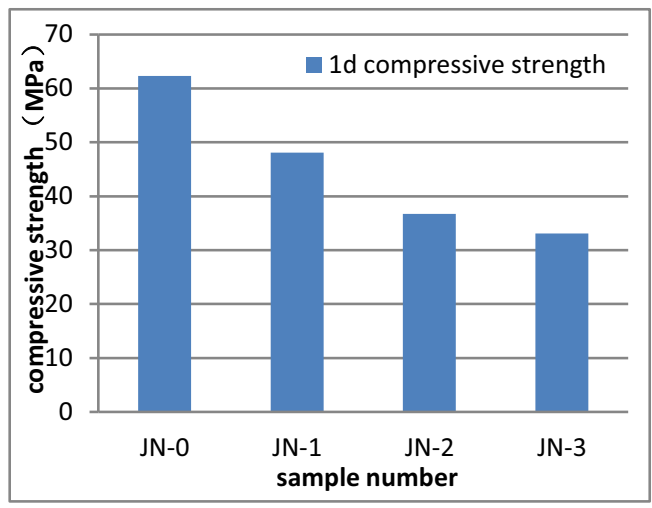

Fig. 12. Variation of compressive strength with changing viscosity reducer content

Based on the above information, we can see that with the increase of viscosity reducer, the viscosity of concrete decreases, but the increase of fluidity is not obvious, which indicates that the addition of organic fiber has a great impact on the fluidity of concrete, and the slight reduction of concrete viscosity is not enough to change the overall flow performance. From the perspective of mechanical properties, the increase of viscosity reducer has no obvious effect on the bending performance of concrete, but has a more obvious impact on the compressive performance, which should be related to the retarder contained in the viscosity reducer ${ }^{[5]}$.

\section{Conclusions}

(1) UHPC is very sensitive to water consumption, so the best water consumption should be determined through the experiment. If the water consumption is too low, the hydration reaction will not be complete, and the strength will be low; if the water consumption is too high, the setting speed of cement will be slow, and it cannot be hardened.

(2) Glass beads and polymer viscosity reducer can slightly improve the fluidity of concrete, but the addition of glass beads has a greater impact on its bending toughness. Polymer viscosity reducer contains retarding components, which will have adverse effects on the compressive strength of concrete.

(3) At present, regulating water consumption is still the main method to control the fluidity of UHPC. Therefore, to ensure the quality of concrete, accurate and 
real-time control of concrete water consumption is needed in production.

\section{Acknowledgments}

This research was financially supported by the Natio nal Key R \& D Program (2017YFC0703700), the N ational Natural Science Foundation of China (518784 04), the Scientific Research Program of Shanghai Sci ence and Technology Commission(18DZ2282600) and the Key Scientific Research Project of Shanghai Co nstruction Engineering Group (18JCYJ-02).

\section{References}

1. WANG De-hui,SHI Cai-jun,WU Lin-mei. (2016) Research and Applications of Ultra-High Perform ance Concrete ( UHPC) in China.Bulletin of the Chinese Ceramic Society,1:141-149.
2. ZHANG Yunsheng,ZHANG Wenhua,CHEN Zhen yu. (2017) A Complete Review of Ultra-high Pe rformance Concrete:Design and Preparation,Micro structure,Mechanics and Durability,Engineering A pplications.Materials Review, 23:1-16.

3. CAO Rongkui. (2008) Study on Mix Proportion Design of Ultra High Performance Concrete Bas ed on CPM Model and Specific Strength.Hunan University.

4. HUO Lin, HE Shun-ai, NIU Yun-hui, YANG F eng-yuan, DONG Wei-ming,QIU Tian,LU Zhongyuan.(2013)Preparation of light-weigh and high-st rength concrete with artificial coarse aggregate.C oncrete, $1: 145-147$.

5. RHEOPLUS 416 ( ${ }^{\circledR}$ Specification of slump prese rving polycarboxylate mother liquor.(2017)BASF chemical building materials (China) Co.,Ltd. 